\title{
Neutron radiography and X-ray computed tomography for quantifying weathering and water uptake processes inside porous limestone used as building material
}

\author{
J. Dewanckele, ${ }^{\mathrm{a}, *}$, T. De Kock ${ }^{\mathrm{a}}$, G. Fronteau ${ }^{\mathrm{b}}$, H. Derluyn ${ }^{\mathrm{c}}$, P. Vontobel $^{\mathrm{d}}$, M. Dierick ${ }^{\mathrm{e}}$, L. Van \\ Hoorebeke ${ }^{\mathrm{e}}$, P. Jacobs ${ }^{\mathrm{a}}$, V. Cnudde ${ }^{\mathrm{a}}$

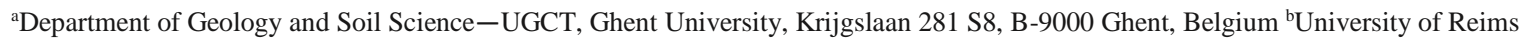 \\ Champagne-Ardenne (URCA), GEGENAA, EA3795 Reims, France ${ }^{c}$ Chair of Building Physics, ETH Zurich, HIL E 47.2, Wolfgang-Pauli- \\ Strasse 15, 8093 Zürich Hönggerberg, Switzerland d Spallation Neutron Source Division, Paul Scherrer Institut (PSI), Villigen, Switzerland \\ ${ }^{\mathrm{e}}$ Department of Physics and Astronomy-UGCT, Ghent University, Proeftuinstraat 86, B-9000 Ghent, Belgium
}

Keywords: Building stone, Weathering, Gypsum, Crust formation, X-ray computed tomography, Neutron , radiography.

\begin{abstract}
:
Euville and Savonnières limestones were weathered by acid test and this resulted in the formation of a gypsum crust. In order to characterize the crystallization pattern and the evolution of the pore structure below the crust, a combination of high resolution X-ray computed tomography and SEM-EDS was used. A time lapse sequence of the changing pore structure in both stones was obtained and afterwards quantified by using image analysis. The difference in weathering of both stones by the same process could be explained by the underlying microstructure and texture. Because water and moisture play a crucial role in the weathering processes, water uptake in weathered and non-weathered samples was characterized based on neutron radiography. In this way the water uptake was both visualized and quantified in function of the height of the sample and in function of time. In general, the formation of a gypsum crust on limestone slows down the initial water uptake in the materials.
\end{abstract}

\section{Introduction}

Deterioration of natural building stones can be regarded as a progress or evolution from fresh stone to complete decay over a certain time period in which different parameters can play an important role [1]. Notwithstanding its complexity, the understanding of alteration, decay or weathering processes of natural stones due to an aggressive environment has made considerable progress in recent years thanks to a multidisciplinary research approach with indirect, direct and predictive measurements. Incorporation of geological knowledge in the field of archaeological research as well as studies of conservation and restoration of natural stones has proven to be beneficial for characterizing building stone materials [2-4]. Geological knowledge also plays a key role in allowing unambiguous choices to be made in restoration problems for degrading natural building materials [5]. Our built cultural heritage has been constructed with finite and non-renewable resources, and therefore exceptional care must be taken in the use of appropriate materials and conservation approaches that both require adequate insights in the involved alteration and eventual weathering processes. Moreover, in the context of sustainability and durability, the research of alteration phenomena inside and at the surface of the stone material seems crucial. 
Dewanckele, J., De Kock, T., Fronteau G., Derluyn, H., Vontobel, P., Dierick, M., Van Hoorebeke, L., Jacobs, P., Cnudde, V. 2014. Neutron radiography and $X$-ray computed tomography for quantifying weathering and water uptake processes inside porous limestones used as building material. Materials Characterization. 88. p. 86-99. http://dx.doi.org/10.1016/j.matchar.2013.12.007

Numerous papers can be found in literature on specific urban deterioration case studies of sedimentary stones [6-15]. Most of these studies concern the interaction between the atmosphere and the stone, resulting in an altered surface layer, usually called crust. Generally, crusts (in most cases due to gypsum formation) can be considered as accumulation of materials on the stone surface. Those accumulations may include both exogenic deposits as well as materials derived from the stone itself and are of great importance to understand the deterioration mechanisms of the stone in its entirety. Quantification of internal dynamic processes still remains difficult with destructive analysis tools. Alteration and deterioration of porous stone are complex processes and its quantification remains difficult. Most attempts to characterize and quantify the induced damage as a function of time are obtained by indirect non-destructive measurements like mass loss weighing, visual inspection, surface observation, and sound speed propagation. Quantitative evaluation of crust formation and erosion processes of stones can for example be addressed by analysing water runoff at frequent time intervals [16]. However, to obtain direct quantitative information about the changing underlying microstructure, most assessment techniques used are destructive. Hence, further research on the same sample becomes difficult and quantification as a function of time thus remains impossible. The assessment of mobilization of elements and (re-)crystallization in porous materials as a function of the stone's underlying microstructure is required in order to elucidate their complex interaction during stone alteration and weathering $[17,18]$. To overcome this major drawback, spatial and time evolving quantitative, non-destructive techniques are mandatory.

It has been demonstrated that non-destructive imaging research with high resolution X-ray computed tomography (HRXCT) turned out to be very valuable for qualitative (visualization of dissolution processes, study of microcrack initiation, pore infilling, etc.) and quantitative (calculation of partial porosity, estimation of dimensional changes, computation of interconnectivity, etc.) characterizations of the pore modification processes in a building stone in full 3D $[19,20,22,23]$. Our main objective is to employ HRXCT, SEM and neutrons to visualize, quantify and interpret alteration and weathering processes inside natural building stones. By performing 3D petrography on weathered and non-weathered zones of material, crucial dimensional information on pore structure evolutions can be obtained. Those evolutions are important for (1) progression of future weathering processes, (2) induced changes in migration paths of water inside the material and ( 3 ) the general decay state of the material. Changes in open and closed porosities, interconnectivity and size distribution can be considered as vital for the interpretation of the durability of materials. As the durability of a material is influenced by its microstructure and texture, different materials will obtain different alteration patterns. The determination of the influence of the building stones' microstructure on weathering processes is therefore of key importance.

In this paper, the weathering behaviour of Euville and Savonnières limestones is investigated with the focus on the crystallization of gypsum and water uptake. Euville and Savonnières are two French limestones frequently used in Belgium for the construction of new buildings and as restoration material. A subvolume of both limestones was analysed in order to try to quantify the pore clogging and pore coalescence due to gypsum formation. A large number of studies have been devoted to gypsum crystallization [17,24-28]. At rain exposed places, the soluble gypsum dissolves in water and no formation of a thick gypsum crust occurs, resulting in a gradual erosion of the surface. In more sheltered places, thick, framboidal gypsum crusts can be formed. As gypsum forms, it acts as a natural passive filter for polluting air particles such as ashes, dust, and soot. As a consequence, building materials will discolour and acquire a more dark to sometimes black layer or patina [29]. Although it is known that gypsum forms on limestone due to the conversion of calcium carbonate by sulphur 
Dewanckele, J., De Kock, T., Fronteau G., Derluyn, H., Vontobel, P., Dierick, M., Van Hoorebeke, L., Jacobs, P., Cnudde, V. 2014. Neutron radiography and $X$-ray computed tomography for quantifying weathering and water uptake processes inside porous limestones used as building material. Materials Characterization. 88. p. 86-99. http://dx.doi.org/10.1016/j.matchar.2013.12.007

dioxide, additional work is needed to fully characterize the processes that control gypsum formation [30]. The contribution of gypsum to the overall deterioration of materials has still not been completely established. However, to assess alteration processes caused by re-crystallizations and to quantify the evolution of the changing, underlying petrophysical properties, artificial weathering is an indispensable step. Descriptions of various standard weathering tests are available (www.nbn.be); by using those tests, a controlled and well known artificially induced atmosphere can be created [25,31].

These gypsum crystallization processes are crucial to evaluate the changes in water uptake, migration of polluted gasses and drying behaviour during weathering. Because water flow and thus weathering largely depends on the materials' pore characteristics, changing structures as described and quantified in this study are of the highest importance for better understanding of the weathering processes, which involve uptake of moisture or water.

In the next section of this paper, the applied methods and the materials are described. The third section presents the results, followed by a discussion in the fourth section. The last section concludes on the main findings of the presented study.

\section{Methods and Materials}

\subsection{Methods}

\subsubsection{Strong Acid Test}

In this study, sulphated encrustations were obtained on both Euville and Savonnières stones in laboratory after an induced strong acid test [20]. Basically, the samples were put in an acid environment according to the European Standard NBN EN 13919 for 21 days [21]. At the bottom of the recipient, a mixture of $500 \pm 10 \mathrm{ml}$ $\mathrm{H} 2 \mathrm{SO} 3(5 \%)$ and $150 \pm 10 \mathrm{ml}$ demineralized $\mathrm{H} 2 \mathrm{O}$ was added. The samples were placed $10 \mathrm{~cm}$ above the mixture. The interaction of the limestone to this environment causes gypsum crystallization on the surface and inside the pore structure. This test is no simulation of rainfall on the material but an exposure to a polluted environment. Before starting the test, the samples were impregnated by water at atmospheric pressure and the relative humidity inside the box amounted to more than $90 \%$ relative humidity. The samples were investigated after 6 and after 21 days in the acid environment.

\subsubsection{High Resolution X-ray CT and Image Analysis}

High resolution X-ray computed tomography (HRXCT) scans were taken on small cylindrical samples (diameter of $1.6 \mathrm{~mm}$ ) of the Euville and Savonnières limestones before the acid test, after 6 days in an acid environment and after 21 days in an acid environment. Before the scans, the samples were dried in a ventilated oven of $60{ }^{\circ} \mathrm{C}$ until no mass difference occurred in a period of $24 \mathrm{~h}$. The experiments were carried out at the Centre for X-ray Tomography at Ghent University (Belgium) [32,33]. The same sample could be measured as a function of time and weathering because HRXCT is a non-destructive technique. For each scan, 1001 projections were registered over an angle of $360^{\circ}$. The total exposure time for each projection image was $3000 \mathrm{~ms}$. A tube voltage of $80 \mathrm{kV}$ and a target current around $32 \mu \mathrm{A}$ was used, resulting in a sufficiently small focal spot. Using a geometrical magnification of approximately 80 , the voxel size obtained was $2.5 \mu \mathrm{m}$ for both limestone series. Taking this voxel size into account, features smaller than $2.5 \mu \mathrm{m}$ cannot be visualized in the reconstructed slices. Because the same 
Dewanckele, J., De Kock, T., Fronteau G., Derluyn, H., Vontobel, P., Dierick, M., Van Hoorebeke, L., Jacobs, P., Cnudde, V. 2014. Neutron radiography and $X$-ray computed tomography for quantifying weathering and water uptake processes inside porous limestones used as building material. Materials Characterization. 88. p. 86-99. http://dx.doi.org/10.1016/j.matchar.2013.12.007

samples had to be scanned several times (before, during and after the acid test), the same scan parameters (filter, exposure time, amount of frames, etc.) were used for each scan during the induced weathering and crust formation process. In addition, the same adjustments like beam hardening correction, normalizing, ring and spot filter, were performed for the reconstruction [34]. To match the reconstructed 3D volumes acquired during the different time intervals and to obtain the same canvas-size, they were visually placed on top of each other in 3D and resliced in VGStudio (C. Afterwards, those volumes were exported and ready to be used for the quantification process. Therefore, the 3D analysis software package Morpho+ was used for the quantification of the microstructural changes before and after the weathering tests [35].

In this study, Morpho+ was mainly used to segment the open pore structure of a subvolume in the scanned dataset. In total, for each sample, 100 slices were analysed $(12 \mathrm{~mm} 3)$. Those 100 slices exclude the top and bottom of the cylindrical samples. The bottom of the samples was not analysed because interaction with the pencil lead could occur. The pencil lead was used to attach the sample to the sample holder on the rotational stage in the X-ray CT system. The top of the sample was excluded because of the curved surface of the sample. By taking this subvolume in the middle of the cylinder, two flat surfaces occur at the bottom and top of the sample, which make the calculations of the radial porosity and radial intersections more transparent. Because by the acid test, the whole surface of the sample was attacked by the acid, crystallizations were present on each slice. Open and closed porosities were calculated by correspondingly measuring the amount of pores in contact with the outer atmosphere (enabling gas and fluid migrations) and the isolated pores, not in contact with the outer atmosphere. Pore size distributions were obtained by defining and evaluating the equivalent diameter of each pore structure. This corresponds to the diameter of a sphere with the same amount of voxels as the original pore structure. Thus, larger equivalent diameters correspond to large pores, while small pores will have smaller equivalent diameters. The equivalent diameter does not provide information about the structure of the pore, but only about its volume. By calculating differences in pore structure before, during and after the artificial weathering test, information of pore clogging and opening can be obtained. However, in order to quantify the superficial pore clogging, an additional step was implemented. The change of the radial intersections of the open pore network before and after 21 days of weathering was quantified. The radial intersections are defined by the openings of the pore structure at the surface of the samples and only limited to a one voxel layer. First the entire (open and closed) pore structure was segmented. Next, all non-border objects (closed pores) were deleted from the volume, as well as objects only attached to the top or bottom of the volume. This was done to ensure that only open pore structures were selected. The changes in aperture were quantified by shrinking the initial volume of interest (VOI) by one voxel in two dimensions. After this shrinkage, the volume of interest was inverted and set as a new VOI. By inverting the volume, a one voxel layer was obtained. Afterwards, a second threshold step was carried out inside this new volume of interest. In this way only the radial intersections of the open pores (1 voxel of thickness) were labelled. A 2D shrinkage of the VOI was necessary because the top and bottom of the subvolume were not the actual borders of the sample.

Avizo $^{\circledR}$ Fire in combination with XLAB HYDRO was used to simulate water flow through the initial nonweathered and weathered states of the Euville limestone. Flow paths were only calculated for this stone, because the percolating porosity of the Savonnières stone was too low for a significant flow to occur. The simulation is 
Dewanckele, J., De Kock, T., Fronteau G., Derluyn, H., Vontobel, P., Dierick, M., Van Hoorebeke, L., Jacobs, P., Cnudde, V. 2014. Neutron radiography and $X$-ray computed tomography for quantifying weathering and water uptake processes inside porous limestones used as building material. Materials Characterization. 88. p. 86-99. http://dx.doi.org/10.1016/j.matchar.2013.12.007

based on the reconstructed, high resolution X-ray CT images of a $1.6 \mathrm{~mm}$ diameter sample. After a segmentation step and removal of non-percolating pore space, the water flow through the samples was calculated by solving Stokes equations. This resulted in a so called velocity field or flow field. The surface of a building material is normally unsaturated and in case of heavy rain, the surface water content rises progressively. At a certain moment in time, the surface becomes saturated. Under these saturated conditions, the flow field is modelled. As pressure difference, 961 Pa was imposed.

\subsubsection{Neutron Radiography}

Capillary uptake experiments were carried out at the NEUtron Transmission RAdiography (NEUTRA) beamline of the SINQ spallation neutron source, situated at PSI (Paul Scherrer Institut, Villigen, Switzerland) [36]. Neutrons transmit rock material easily, whereas water blocks the transmission. Consequently, neutrons are ideally suited for visualizing water inside natural building stones. The neutron energy at NEUTRA has a thermal Maxwellian distribution with maximum at $25 \mathrm{meV}$. The detector consists of a CCD camera looking over a mirror onto a scintillator. The scintillator was a mixture of ZnS powder, doped with $6 \mathrm{Li}$ with a thickness of $100 \mu \mathrm{m}$. A nominal pixel size of $100 \mu \mathrm{m}$ was achieved and the exposure time per radiograph was around $10 \mathrm{~s}$. Samples were taped with aluminium (which is transparent for neutrons), leaving the top and bottom open for transport of water and gases. Afterwards, they were placed in-between source and detector and water was remotely added. Because neutrons mainly scatter, they may influence the estimation of the water content present in the stone. The attenuation of water is rather due to scattering than to absorption, thus a correction is needed because the scattered neutrons still reach the detector [37,38]. A correction algorithm (QNI method) developed by Hassanein et al. was used to accurate the data and to determine the volumetric water content inside the stone samples [38].

A dark-field and flat-field image correction was performed, together with a background scattering correction. The latter was done by placing a body which is opaque for neutrons in front of the experimental setup and acquiring a black-body correction image. The measured neutron flux behind this body, mostly a boron block, is called the background scatter. In addition, also the sample scattering is corrected in the QNI method. This kind of scattering underestimates the amount of water inside the samples [37,38]. By calculating the sample scattering in an iterative process, a more accurate corrected radiograph could be obtained. By working with the QNI method, series of grey scale radiographs were transformed into images with a quantitative moisture content in gram per pixel.

In total, sixteen samples were processed with the QNI method. Four samples of weathered Euville, four samples of weathered Savonnières, four reference samples of un-weathered Euville and four reference samples of unweathered Savonnières. The weathering was obtained by the strong acid test. In the case of the weathered samples, the recrystallized surface was placed on the bottom, 4-6 $\mathrm{mm}$ under the water surface. The thickness of the samples amounted $30 \mathrm{~mm}$, and the height and width were 50 by $30 \mathrm{~mm}$. For the Savonnières stone, two samples were set perpendicular to the bedding plane and two samples parallel with it. A reference radiograph of the initial dry sample was taken and subtracted afterwards from the series of radiographs. By dividing each sample in 50 height intervals, mean water content values were obtained not only in function of height but also in function of time. Before and after the water uptake experiments with neutrons, all samples were weighted with a mass balance in order to calculate the amount of water absorbed. 
Dewanckele, J., De Kock, T., Fronteau G., Derluyn, H., Vontobel, P., Dierick, M., Van Hoorebeke, L., Jacobs, P., Cnudde, V. 2014. Neutron radiography and $X$-ray computed tomography for quantifying weathering and water uptake processes inside porous limestones used as building material. Materials Characterization. 88. p. 86-99. http://dx.doi.org/10.1016/j.matchar.2013.12.007

\subsubsection{Petrographical Microscope and SEM-EDS}

Scanning electron microscopy with an energy-dispersive X-ray detector (SEM-EDS) was used to visualize and analyse the changes that occurred inside Euville and Savonnières limestones after gypsum crystallization. A JSM 5310LV system was used. A working distance around $3 \mathrm{~mm}$ was installed with an accelerating voltage of $15 \mathrm{kV}$. For each mapping, 70 frames were made with a measuring time of $60 \mathrm{~s}$. The same samples that were scanned with HRXCT were used for an internal investigation with SEM. After the HRXCT measurement, the sample was imbedded in resin and reduced in length by polishing to obtain an internal surface. Measurements and general characterization of the stones was obtained by petrographical microscopy (Axio Scope A1).

\subsection{Materials}

\subsubsection{Euville Limestone}

Euville limestone (Oxfordian, Late Jurassic) is a grainstone composed of large crinoid fragments with a syntaxial overgrowth of calcite. The outcrops of the limestone are situated near Commercy (Département de la Meuse, France). The French term 'Entroquite de la Meuse' is frequently used to group Euville, Lérouville, Moulin-à-vent and other local and commercial stone names. The crinoid sedimentary structures of Euville have a discontinuous lenticular geometry and are part of the inter-reef units that rest on the sides of reef formations [39]. On top they are covered by chalk. The sedimentary body is $2.5 \mathrm{~km}$ long with a width of $600 \mathrm{~m}$ and a maximum thickness of 20 $\mathrm{m}$ [39]. The samples used in this work are derived from the ROCAMAT (www.rocamat.com) quarry in Euville, France. The formation around Euville from the middle Oxfordian is characterized by a complex succession of coral bioherms, separated by inter-reef zones. Visually, Euville is easily recognizable. Diagnostic characteristics of the stone are a shiny appearance on fresh-cut surfaces, a white-beige to pink colour and a grain-like structure due to a loose packing of the crinoid fragments. Similar to the Savonnières stone, it is almost completely (98\%) composed of calcium carbonate. The crinoid fragments are between 0.5 and $2 \mathrm{~mm}$ in length and the average measured diameter in thin section was around $900 \mu \mathrm{m}$. Besides these particles also fragments of Echinodermata (sea urchins), brachiopods, coral fragments and pellets are distinguishable.

The syntaxial cement occupies a large part of the stone and results in a granular cohesion (Fig. 1). Often the cementation occupies the intergranular space completely and no porosity remains. In other zones, the syntaxial cement stops abruptly with sharp corners and edges and does not connect the grains. The overgrowth of syntaxial cement has an average size in thin sections of around $150 \mu \mathrm{m}$ but large cemented zones with a diameter around $500 \mu \mathrm{m}$ were also detected. Some crinoid fragments are broken and both parts were afterwards recrystallized within a single monocrystal with different extinction angles. Shell fragments are bordered with a thin (10-20 $\mu \mathrm{m})$ sparitic cement or even micritic cement and within some fragments larger $(40 \mu \mathrm{m})$ sparite was recognized. The porosity of the stone amounts to $10 \%$ or even up to $20 \%$. Macropores are present in-between the syntaxial overgrowth of the particles and are very heterogeneous. The micropores are often intraparticle or are situated between the micrite and sparite crystals around shell fragments. In addition, some microporosity occurs due to micritized intraclasts and crinoid fragments [40]. The apparent mass of the stone amounts $2245.9 \pm 18.3 \mathrm{~kg} / \mathrm{m} 3$ [41]. The Euville limestone is a famous building stone not only in France, but also in Belgium [40,42] where it is often used in combination with Savonnières limestone and Lede stone. 
Dewanckele, J., De Kock, T., Fronteau G., Derluyn, H., Vontobel, P., Dierick, M., Van Hoorebeke, L., Jacobs, P., Cnudde, V. 2014. Neutron radiography and $X$-ray computed tomography for quantifying weathering and water uptake processes inside porous limestones used as building material. Materials Characterization. 88. p. 86-99. http://dx.doi.org/10.1016/j.matchar.2013.12.007
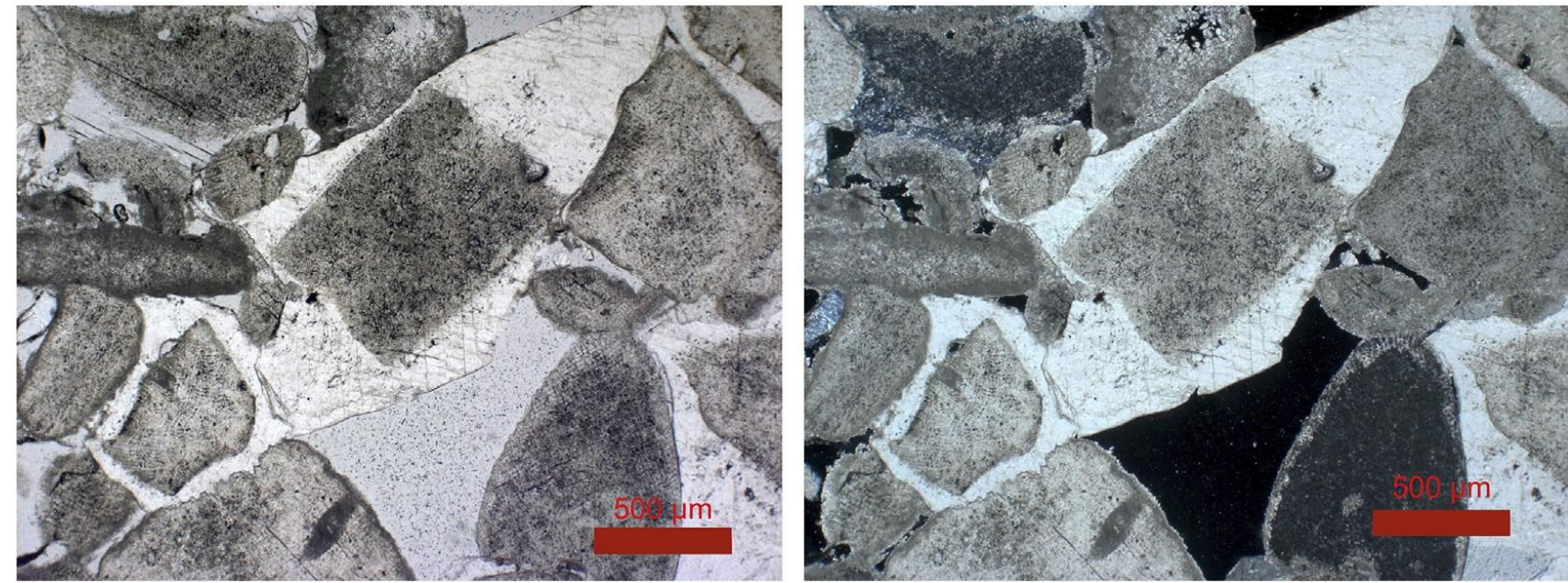

Fig. 1 - Thin section of Euville limestone in planar polarized light (left) and crossed polarized light (right) (50x magnification, scale bar $500 \mu \mathrm{m}$ ). Crinoid fragments overgrown with syntaxial cement are visible. Due to these irregular recrystallizations large intergranular pores remain.

\subsubsection{Savonnières Limestone}

Savonnières limestone is a soft, buff-coloured, French oolitic limestone (Late Jurassic, Tithonian). Both historical and active quarries are located between Bar-le-Duc, St-Dizier and Joinville (Départements de la Meuse et Haute-Marne, France). The ancient extraction quarries were underground but are abandoned now; only three active, open-pit quarries remain. The stone samples studied in this work originate from the ROCAMAT quarry in Savonnières-en-Perthois (Départment de la Meuse, France) and are known under the name Savonnières 1/2 fine. Savonnières limestone belongs to the Oolithe Vacuolaire, a stratigraphical unit that also includes the Brauvillier stone, Chévillon stone, Combles stone and other local variations. Their microfacies is very diverse and is mainly characterized by hollow ooids, shell fragments, pellets and the presence of dolomite.

The Savonnières limestone is an almost pure calcitic limestone containing oolites (average diameter around $500 \mu \mathrm{m}$ ) and shell fragments (Fig. 2). Very concentrated zones of shell fragments (more than 50 vol.\%) often occur in the Oolithe Vacuolaire. Remarkable are the hollow cores of the ooids and ooid fragments. These hollow cores are formed during a diagenetic phase in which dissolution mostly occurred in the faecal pellets (high magnesium content), leaving the cortex (lowmagnesiumcontent)and sparite cementaroundthe cortex unaffected. Also, shell fragments are often dissolved leaving only the perimeter intact.

Isopachous bladed cement (or dogtooth cement) occurs between the ooids. This sparite cement fills partially the intergranular porosity and is formed through an additional crystallization phase. Lengths of $100 \mu \mathrm{m}$ sparitic cement crystallizations are very common in this type of stone. Because the bladed cement is not completely infilling the intergranular porosity, a large and open interconnected pore structure is still existing. Frequently, the original acicular cement around the grains is visible. In most grains, the bladed cement is detached from the grains and results in porous zones with openings between $50 \mu \mathrm{m}$ and $100 \mu \mathrm{m}$ which are connected to the interconnected intergranular pore structure. In some rare cases, also parts from the outer cortex of the ooid fragments are detached. Moreover, severe cracking and deformation of the grains predominates the studied microfacies. 
Dewanckele, J., De Kock, T., Fronteau G., Derluyn, H., Vontobel, P., Dierick, M., Van Hoorebeke, L., Jacobs, P., Cnudde, V. 2014. Neutron radiography and $X$-ray computed tomography for quantifying weathering and water uptake processes inside porous limestones used as building material. Materials Characterization. 88. p. 86-99. http://dx.doi.org/10.1016/j.matchar.2013.12.007

Because of the hollow ooid and shell fragments, the total porosity is much higher than the well-cemented Flemish natural building stones (such as the Lede stone). Values of $30 \%$ to $40 \%$ porosity are demonstrated within the macropores in the ooid itself (hollow cores) and in-between the cement and micropores in the cortex of the ooid. The stone is extensively used as building material in Belgium for replacing the Lede stone and for the construction of new buildings [42]. The apparent mass of the stone amounts $1793.2 \pm 9.6 \mathrm{~kg} / \mathrm{m} 3$ [41].
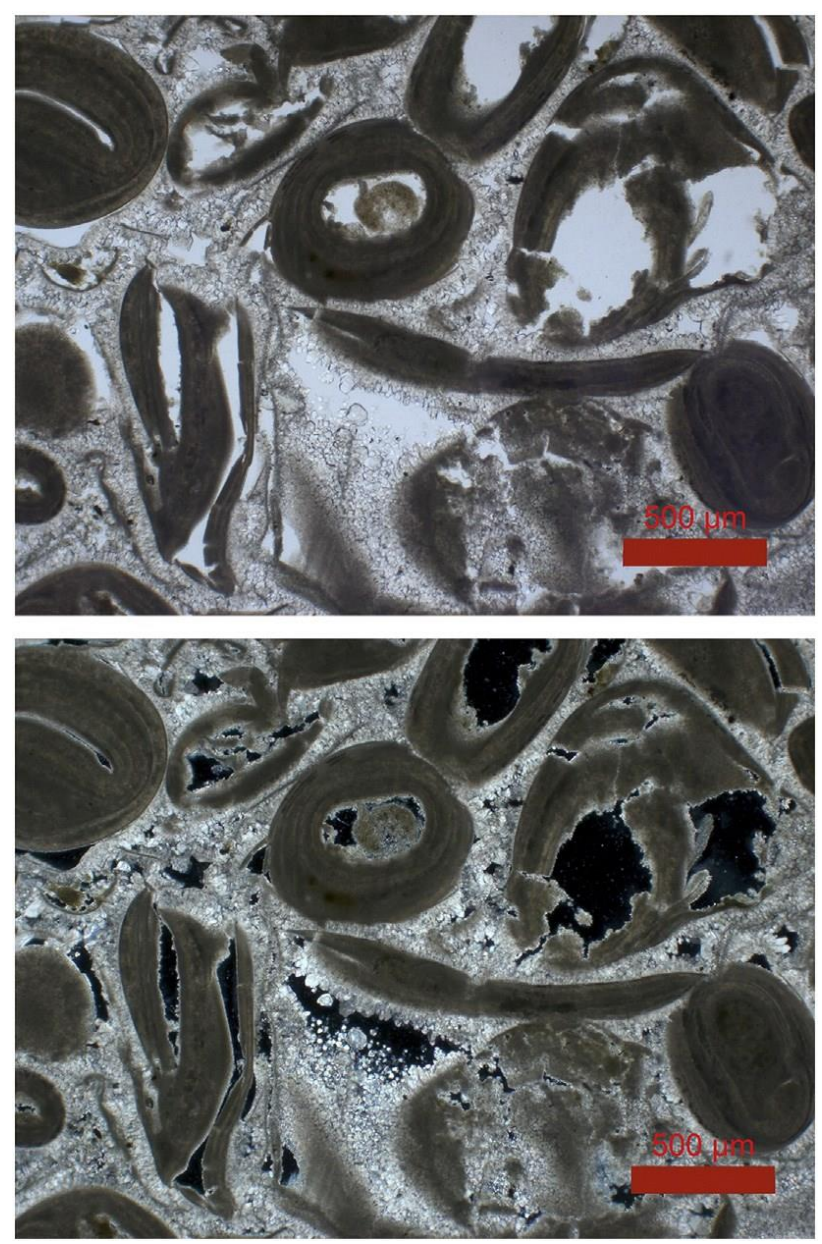

Fig. 2 - Thin section of Savonnières limestone in planar polarized light (top) and crossed polarized light (bottom) (50x magnification, scale bar $500 \mu \mathrm{m}$ ). Hollow ooid cores are visible as well as severe cracking of the grains. The grains are cemented by a typical bladed palissadic cement. Because the cement is not occupying all the intergranular space, a large, interconnected porous structure remains in-between the grains.

\section{Results}

\subsection{Gypsum Crystallization}

\subsubsection{Euville}

A cylindrical core of Euville limestone (diameter of $1.6 \mathrm{~mm}$ ) was scanned before, after 6 and after 21 days of weathering by strong acid. By comparing the 3D rendered volume, derived from the HRXCT, after 6 days of weathering, an external thick gypsum layer is clearly visible on the crinoid fragments (Fig. 3). Below this layer, a porous zone is noticeable, formed due to partially dissolved crinoid fragments. 


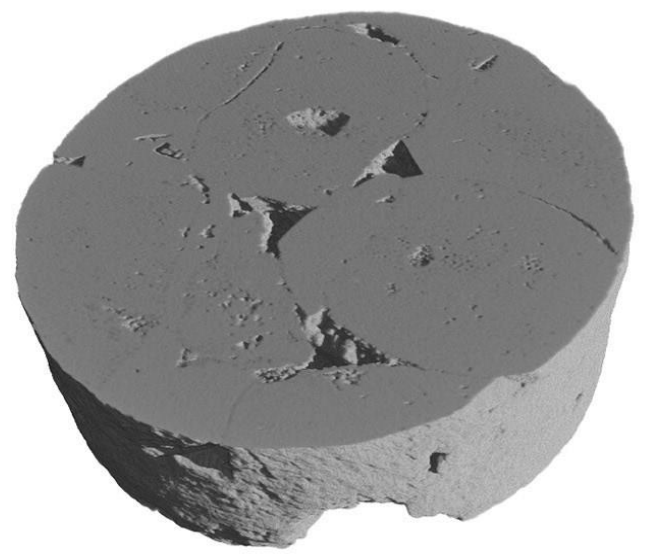

Before test
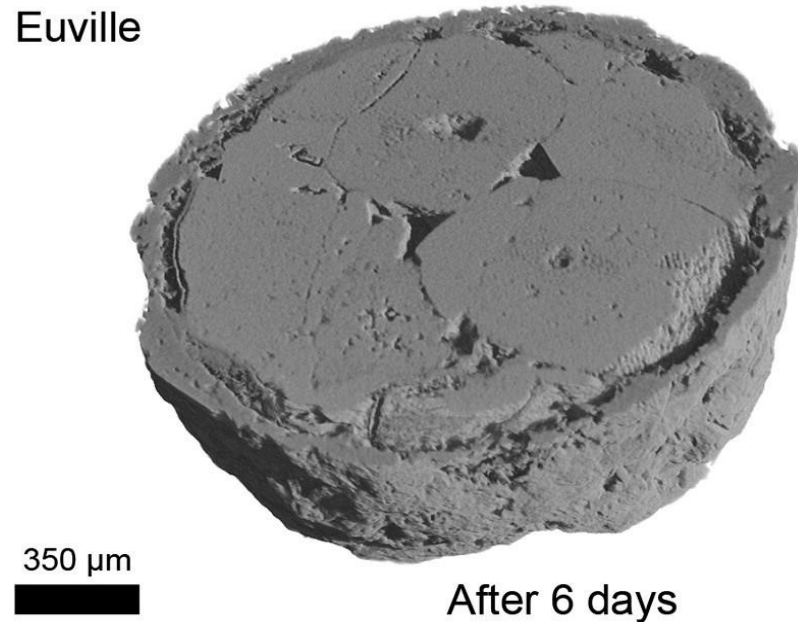

After 6 days

Fig. 3-3D rendered volumes of the unweathered (left) and weathered (right) states of the Euville limestone. A thick gypsum crust on top of the crinoid fragments is visible, with a porous layer underneath. The voxel size is $2.5 \mu \mathrm{m}$.
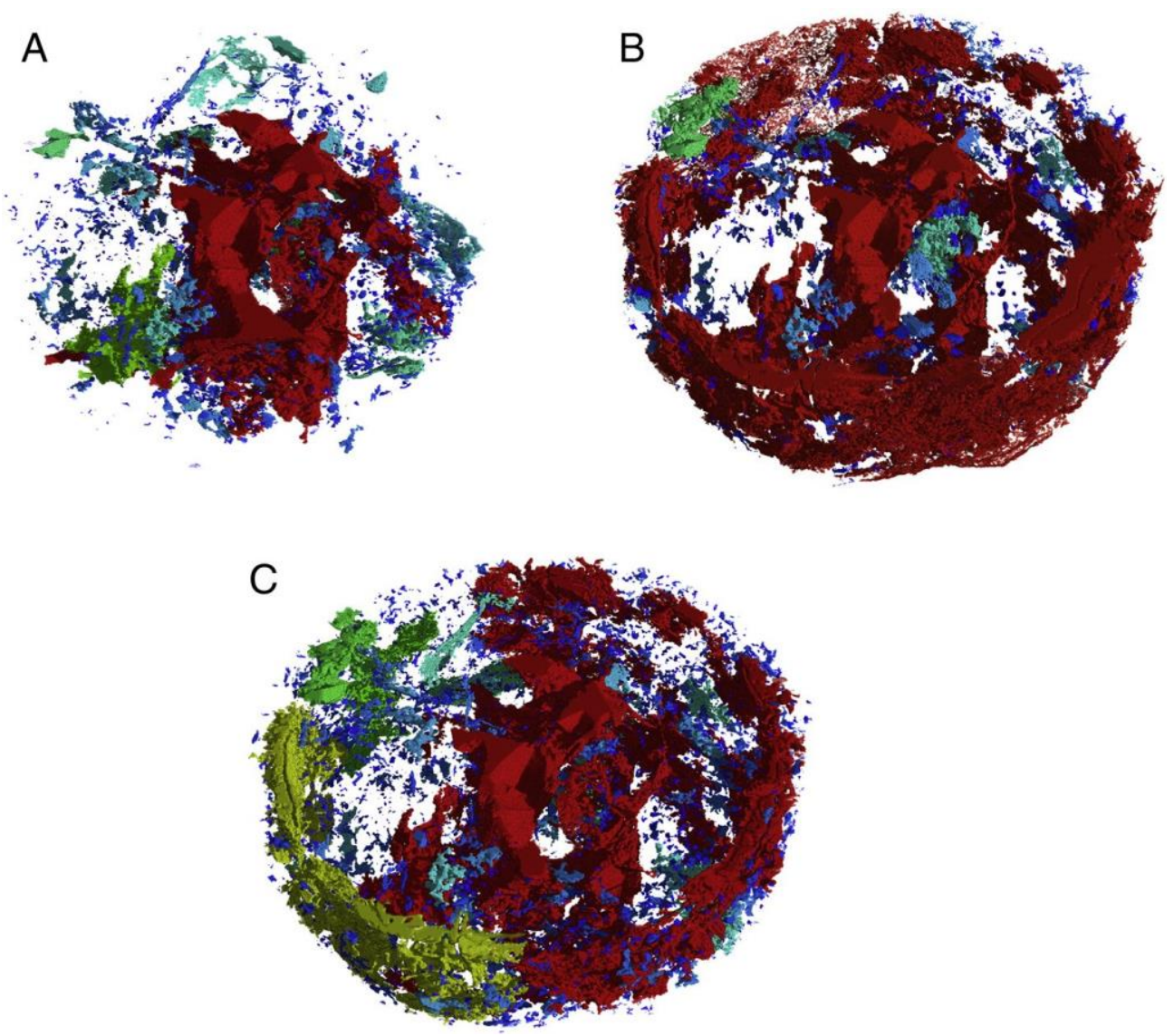

Fig. 4-3D rendered volumes of the changing pore structure in the Euville limestone. The pores are colour coded according to the equivalent diameter. Colours are a transition from red (large connected pore) to blue (small pore). A) Unweathered state; B) after 6 days and C) after 21 days of weathering. Core diameter is $1.6 \mathrm{~mm}$ and voxel size is $2.5 \mu \mathrm{m}$. (For interpretation of the references to colour in this figure legend, the reader is referred to the web version of this article.) 
Dewanckele, J., De Kock, T., Fronteau G., Derluyn, H., Vontobel, P., Dierick, M., Van Hoorebeke, L., Jacobs, P., Cnudde, V. 2014. Neutron radiography and $X$-ray computed tomography for quantifying weathering and water uptake processes inside porous limestones used as building material. Materials Characterization. 88. p. 86-99. http://dx.doi.org/10.1016/j.matchar.2013.12.007

In Fig. 4, the porous structure inside the Euville stone is selected and labelled according to their equivalent diameter in order to obtain information on internal crystallization and recrystallization processes. The 3D rendered pore structure shows the transformation of the pore structure before (A), after 6 days (B) and after 21 days (C) in an acid environment. After 6 days, the porous layer, created through dissolution just beneath the crust, connects the original pore network by coalescence of pores (coloured red). Before the weathering test, the total porosity amounted $5.7 \%$ and increased after 6 days to $8.1 \%$. In this case, the formation of secondary porosity just behind the newly formed exterior gypsum layer and inside the sample prevailed upon the crystallization of gypsum inside the pores located in the sample's interior. After 21 days, the secondary formed pore structure fragmented (as can be seen in Fig. 4C) due to recrystallizations of calcium carbonate and crystallizations of gypsum inside. The distinction between both is done with SEM-EDS analysis. In addition, after 21 days, numerous smaller pores (blue in Fig. 4C) are formed around the surface of the sample. The porosity slightly increased to $8.2 \%$ at the end of the test. From the initial situation to the final situation, the open porosity (visualized in red in Fig. 4) (porosity in contact with the surface of the sample enabling fluid and gas migration) significantly increased.

The porous layer, created through dissolution just beneath the crust, connects the original pore network by coalescence of pores. Before the test, the biggest interconnected pore (equivalent diameter of $432 \mu \mathrm{m}$; red in Fig. 4A) amounted to almost 80 vol.\% of the total porosity of the stone. This is demonstrated by the pore size distribution before during and after the test and shown in Fig. 5. In this figure the volume\% of the total porosity is plotted in function of a given equivalent diameter (ED) interval. After 6 days of weathering, the interconnected pore network (red in Fig. 4B) obtained an equivalent diameter of $537 \mu \mathrm{m}$ and amounted $6.9 \%$ of the porosity of the stone. In addition almost 5000 new pores were formed with an ED smaller than $100 \mu \mathrm{m}$. After 21 weathering days, the interconnected network fragmentises (red, yellow, green in Fig. 4C) due to new crystallizations in the pore structure. As a result, new pore structures with an ED between 100 and $300 \mu \mathrm{m}$ are created. On top of the previously formed gypsum layer, at the surface of the sample, around 1000 new pores were formed with an equivalent diameter smaller than $100 \mu \mathrm{m}$ (blue in Fig. 4C).

In order to obtain a better insight in the surface processes of the gypsum crystallization, the radial intersections or openings of the open pore structure were quantified. The typical large radial intersections of the open pore structure of the Euville stone were almost totally covered with gypsum and fragmented into numerous smaller radial intersections due to the formation and covering of a thick gypsum crust. More than 500 new radial intersections with an opening smaller than $200 \mu \mathrm{m} 2$ were formed during the covering process of the initial large (bigger than $2000 \mu \mathrm{m} 2$ ) pore structure by crystallization of gypsum fragments.

Fig. 6 shows a SEM image and corresponding EDS mapping of sulphur. On the EDS mapping, a thick (100-200 $\mu \mathrm{m}$ ) gypsum layer is visible on the surface of the sample. Inside the open pore structure of the stone, a thin (only $10 \mu \mathrm{m}$ thick) gypsum layer was noticeable. No preferential weathering of bioclasts was visible inside the stone.

\subsubsection{Savonnières}

Similar to the Euville stone, also a cylindrical core of the Savonnières stone was scanned before, during and after weathering in an acid environment. The 3D rendered volumes before and after 6 days of weathering are shown in Fig. 7. In contrast to the Euville stone, no thick external gypsum layer was formed, but a non-porous layer of gypsum and calcium 
Dewanckele, J., De Kock, T., Fronteau G., Derluyn, H., Vontobel, P., Dierick, M., Van Hoorebeke, L., Jacobs, P., Cnudde, V. 2014. Neutron radiography and $X$-ray computed tomography for quantifying weathering and water uptake processes inside porous limestones used as building material. Materials Characterization. 88. p. 86-99. http://dx.doi.org/10.1016/j.matchar.2013.12.007

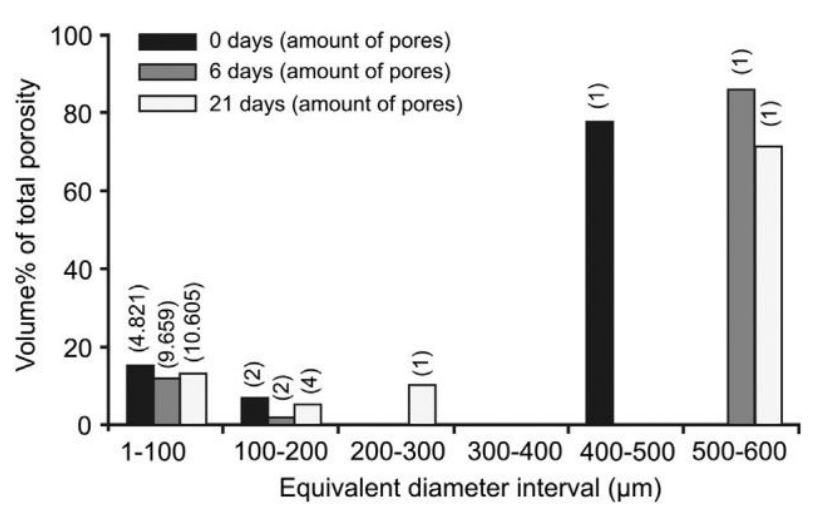

Fig. 5 - Pore size distribution obtained with HRXCT in the Euville limestone.

The volume percentage of the total porosity is given for each equivalent diameter interval after 0 days (black), 6 days (dark grey) and 21 days (light grey). On top of each bar, the total amount of pores is shown. carbonate as indicated by the white arrow in Fig. 7. In addition, some ooids in the rendered volumes are partially recrystallized andcan beidentified by a partial lossofthe internal structure of the porous cortex of the particles. By importing the volumes in Morpho+, the changes of the pore structure inside were quantified: a gradual decrease of the total porosity was noticed. Before the test, the total porosity amounted to $11.6 \%$; after 6 days of weathering $10.4 \%$ and after 21 days $9.8 \%$. Also the amount of open porosity slightly decreased with continuation of the test. Ascan be seen inFig.8, the crystallizationofgypsum and recrystallization of calcium carbonate results in a clogging of the open pore network. Similar to the Euville stone, the pores inside the limestone are labelled according to their ED, whereby red represents the largest pores and blue the smallest. Gradually, after 6 and 21 days of weathering, the pores become disconnected by crystallizations inside resulting in a fragmentation of the original network.
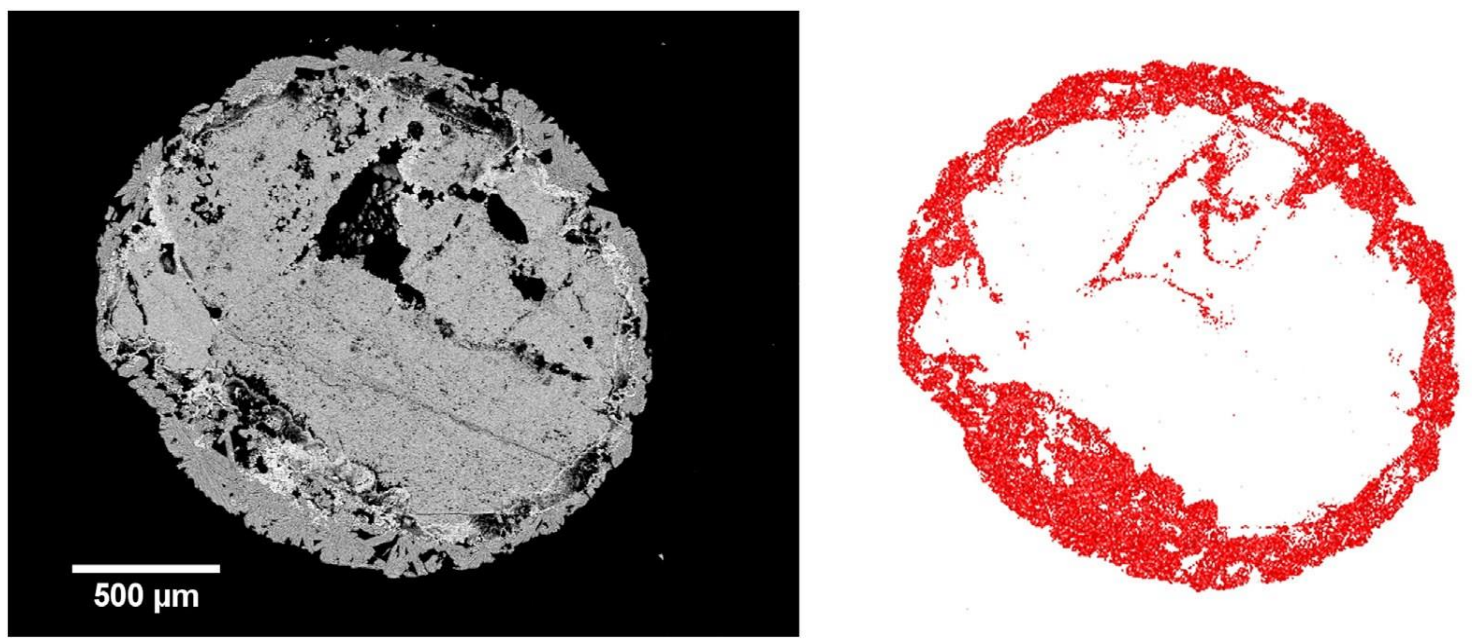

Fig. 6 - SEM image of weathered Euville limestone (left) and mapping of the sulphur-element (right). 
Dewanckele, J., De Kock, T., Fronteau G., Derluyn, H., Vontobel, P., Dierick, M., Van Hoorebeke, L., Jacobs, P., Cnudde, V. 2014. Neutron radiography and $X$-ray computed tomography for quantifying weathering and water uptake processes inside porous limestones used as building material. Materials Characterization. 88. p. 86-99. http://dx.doi.org/10.1016/j.matchar.2013.12.007

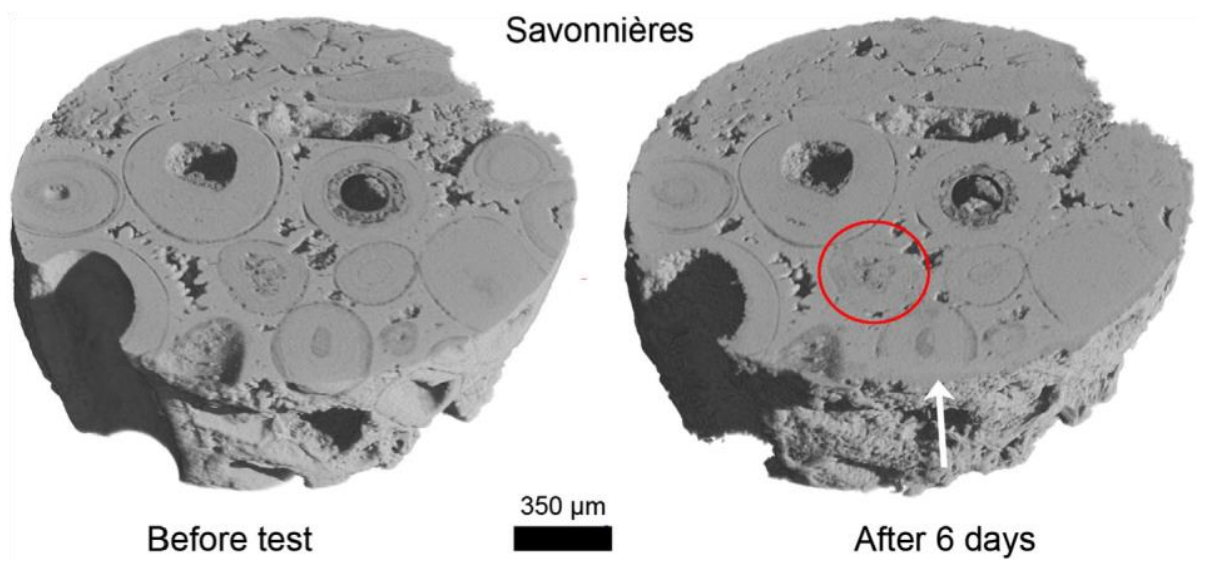

Fig. 7 - 3D rendered volumes of the unweathered (left) and weathered (right) states of the Savonnières limestone. A transformed layer is visible on the surface of the sample (white arrow) in combination with an infilling of the cortex of some ooid fragments (red circle). The voxel size is $2.5 \mu \mathrm{m}$. (For interpretation of the references to colour in this figure legend, the reader is referred to the web version of this article.)
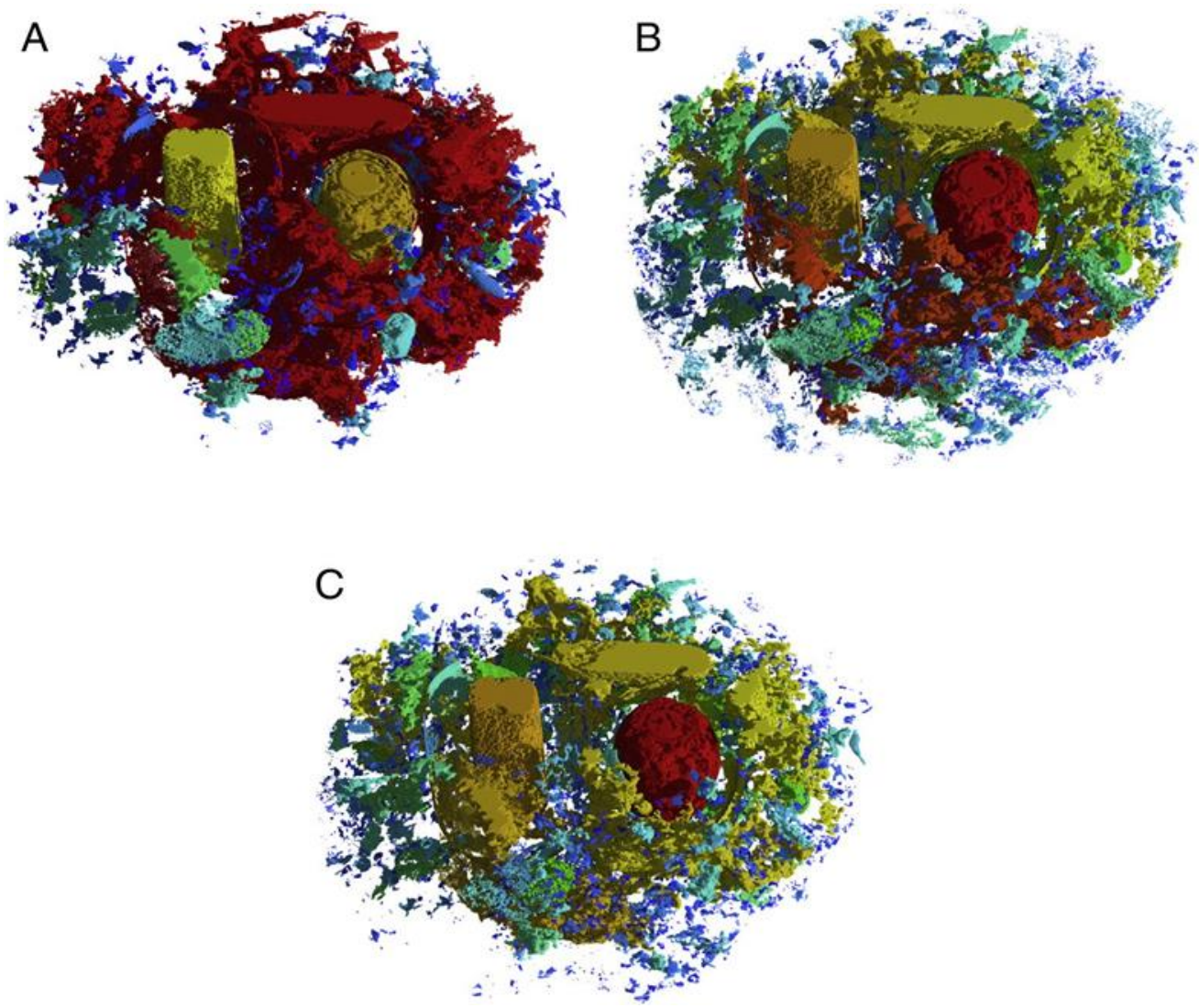

Fig. 8-3D rendered volumes of the changing pore structure in the Savonnières limestone. The pores are colour coded according to the equivalent diameter. Colours are a transition from red (large connected pore) to blue (small pore). A) Unweathered state; B) after 6 days and C) after 21 days of weathering. The core diameter is 1.6 $\mathrm{mm}$ and the voxel size is $2.5 \mu \mathrm{m}$. (For interpretation of the references to colour in this figure legend, the reader is referred to the web version of this article.) 
Dewanckele, J., De Kock, T., Fronteau G., Derluyn, H., Vontobel, P., Dierick, M., Van Hoorebeke, L., Jacobs, P., Cnudde, V. 2014. Neutron radiography and $\mathrm{X}$-ray computed tomography for quantifying weathering and water uptake processes inside porous limestones used as building material. Materials Characterization. 88. p. 86-99. http://dx.doi.org/10.1016/j.matchar.2013.12.007

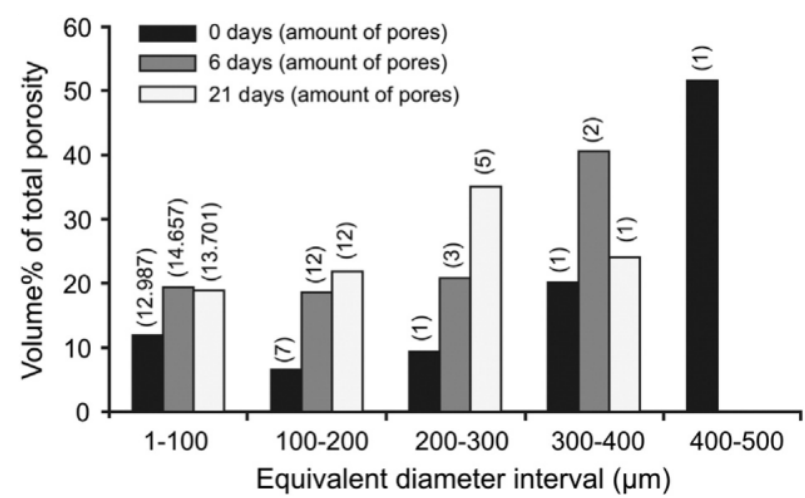

Fig. 9 - Pore size distribution obtained with HRXCT in the Savonnières limestone. The volume percentage of the total porosity is given for each equivalent diameter interval after 0 days (black), 6 days (dark grey) and 21 days (light grey). On top of each bar, the total amount of pores is shown.
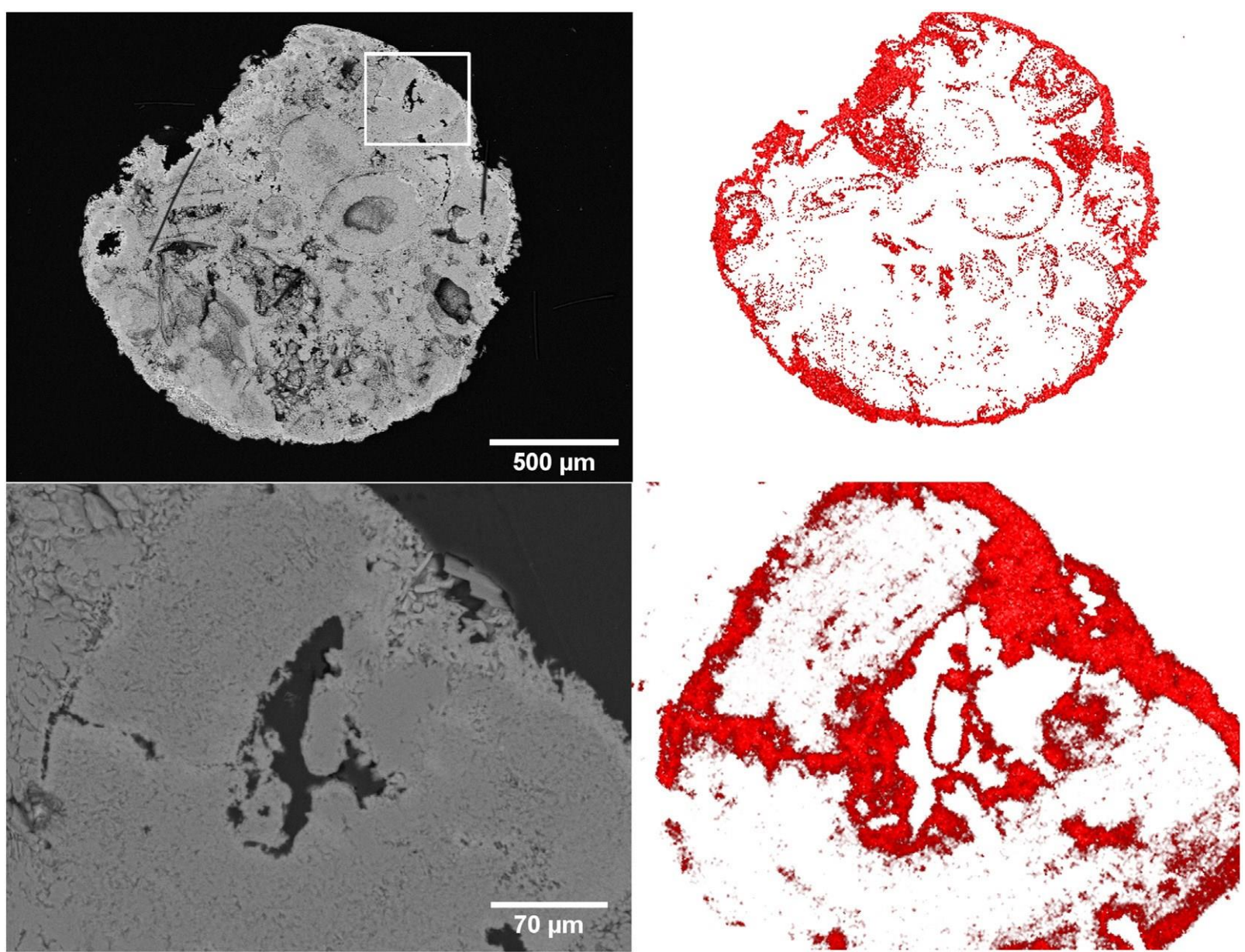

Fig. 10 - SEM image of weathered Savonnières stone (left) and corresponding sulphur-mapping (right).

Fig. 10 shows SEM images (left side) and corresponding EDS mapping of sulphur in red (on the right side). The second row shows a detail of the weathered ooid from the zone indicated by the white box. On the overall mapping, gypsum is present at the surface of the core and on the cortex of the ooid fragments. On the detailed mapping of the ooid, the gypsum crystallizations are concentrated along cracks inside the ooid and seem to follow 
Dewanckele, J., De Kock, T., Fronteau G., Derluyn, H., Vontobel, P., Dierick, M., Van Hoorebeke, L., Jacobs, P., Cnudde, V. 2014. Neutron radiography and $X$-ray computed tomography for quantifying weathering and water uptake processes inside porous limestones used as building material. Materials Characterization. 88. p. 86-99. http://dx.doi.org/10.1016/j.matchar.2013.12.007

the concentric orientated structure. On places where the sparitic cement was detached from the ooid, concentrations of gypsum crystallizations were visible.

An overview of the pore size distribution is shown in Fig. 9. The original connected pore network with an ED of $462 \mu \mathrm{m}$ made $52 \mathrm{vol} . \%$ of the total porosity of the stone. Two pores, one with an ED of $338 \mu \mathrm{m}$ and the other 263 $\mu \mathrm{m}$, correspond to two hollow cores inside ooid fragments and are isolated from the interconnected porous network. Even during and after crystallization they do not become connected to the intraparticle porosity. After 6 days in an acid environment, 1670 pores are formed with an ED smaller than $100 \mu \mathrm{m}$ due to crystallization inside and fragmentation of the original pore structures. This fragmentation continues and after 21 days the largest volume\% of the total porosity (35\%) only has an ED around $200 \mu \mathrm{m}$.

Similar to the Euville stone, the radial intersections or openings of the open pore structure were quantified. Initially, the radial intersections of the Savonnières limestone are relatively large due to the hollow cores of the ooid grains, which are, apart from the porous structure in the sparite cement, responsible for water uptake and flow. After crystallizations, the radial intersections become smaller but their position and shape did not change significantly. Only the amount of smaller radial intersections (below $500 \mu \mathrm{m} 2$ ) increased slightly, while the surface area of the larger radial intersections decreased significantly.

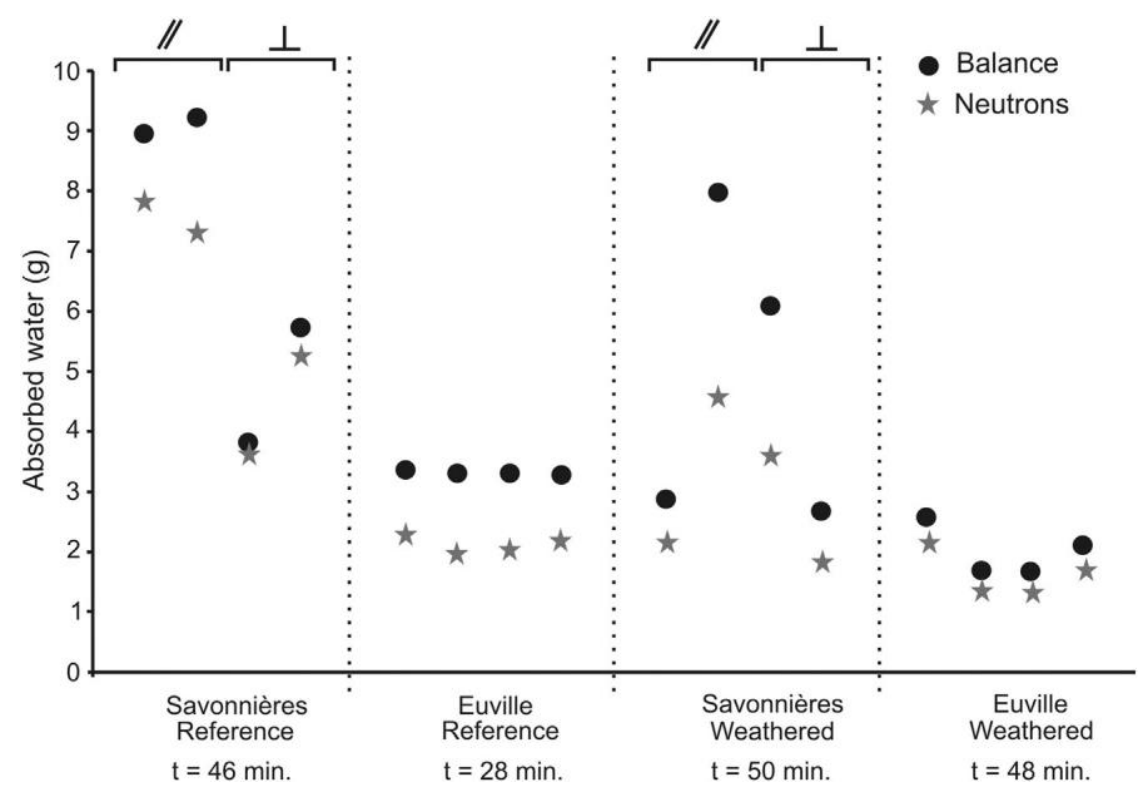

Amount of water absorbed after the water uptake experiments on unweathered and weathered limestones measured with neutrons and by means of mass balance on the same sample. For the Savonnières stone two samples parallel and two samples perpendicular to the bedding plane were measured

Fig. 11 - Amount of water absorbed after the water uptake experiments on unweathered and weathered limestones measured with neutrons and by means of mass balance on the same sample. For the Savonnières stone two samples parallel and two samples perpendicular to the bedding plane were measured.

Fig. 11 demonstrates that the results obtained with neutrons are significantly lower than the gravimetrical results. After crust formation, the amount of water present in the stones is lower than without crust. For a more homogeneous stone such as the Euville stone, this can be directly observed from the graph. For theSavonnières 
Dewanckele, J., De Kock, T., Fronteau G., Derluyn, H., Vontobel, P., Dierick, M., Van Hoorebeke, L., Jacobs, P., Cnudde, V. 2014. Neutron radiography and $X$-ray computed tomography for quantifying weathering and water uptake processes inside porous limestones used as building material. Materials Characterization. 88. p. 86-99. http://dx.doi.org/10.1016/j.matchar.2013.12.007

stone, which is more heterogeneous because of its prominent bedding, it seems that more samples have to be investigated in order to make substantial conclusions. However, it can be seen that the water content measured parallel to the bedding significantly decreased. The results in Fig.11 show only the final situation of the experiment and for the whole sample. In order to quantify the water content in function of height inside the sample and time, 2D moisture distribution curves were calculated (Fig. 12).

\subsection{Water Uptake Experiments}

\subsubsection{Neutron Radiography}

As could be seen with HRXCT, superficial crusts in both the Euville and Savonnières stones were formed after the induced weathering test. As water and moisture are key factors for the deterioration of building materials, capillarity tests were performed in order to quantify the impact of the weathering crust. The focus of those tests was to look at the initial water uptake inside the unweathered and weathered stones. As neutrons and X-rays interact differently with matter, both techniques are complementary. Water, boron and chloride can be easily detected with neutrons, so this technique has been used for the identification of water inside the stones during capillary uptake. Results of the final amount of absorbed water after the capillary uptake tests are shown in Fig. 11.
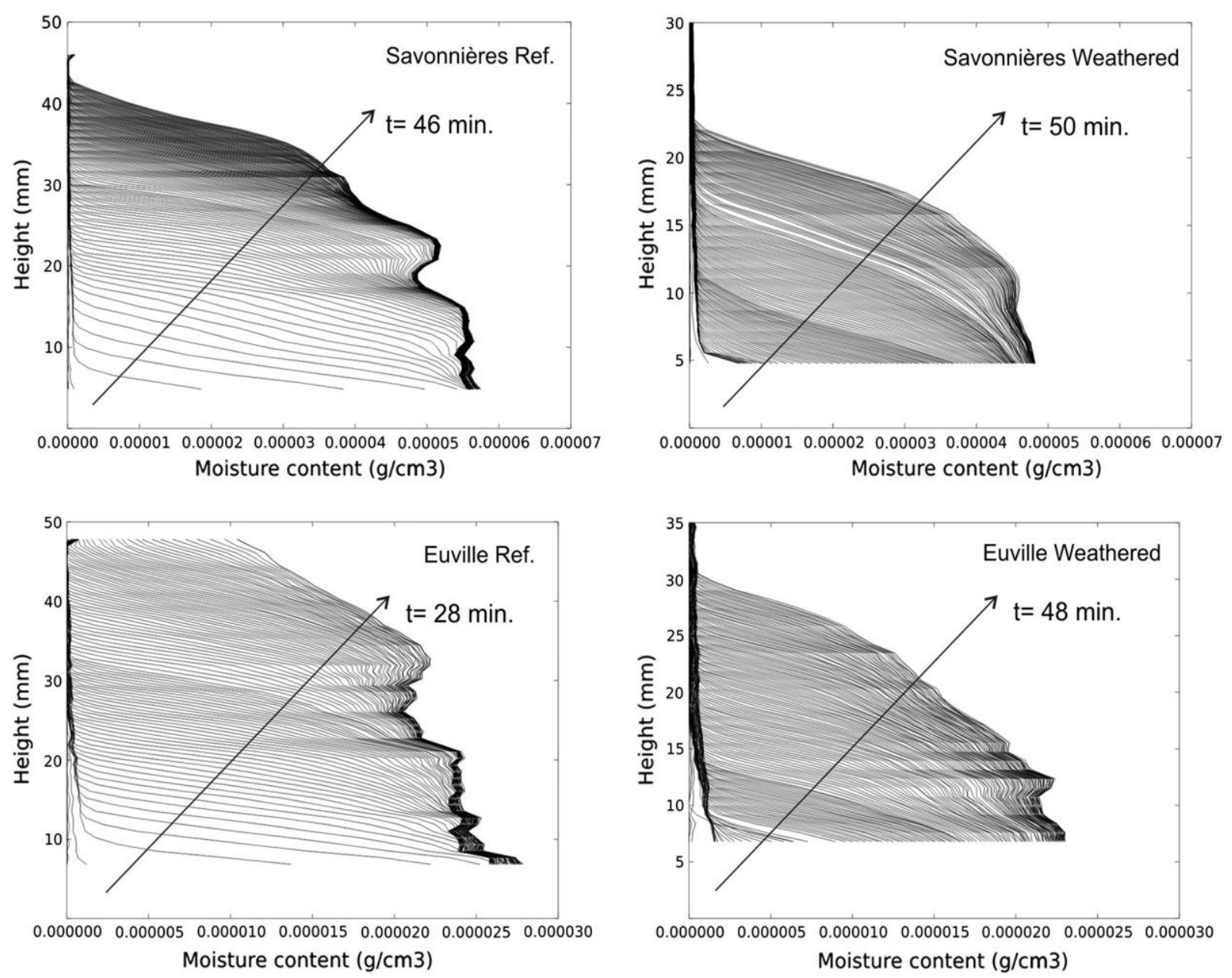

Fig. $12-2 D$ moisture profiles at intervals of $12 \mathrm{~s}$ for the whole duration of the water uptake test. 
Dewanckele, J., De Kock, T., Fronteau G., Derluyn, H., Vontobel, P., Dierick, M., Van Hoorebeke, L., Jacobs, P., Cnudde, V. 2014. Neutron radiography and $X$-ray computed tomography for quantifying weathering and water uptake processes inside porous limestones used as building material. Materials Characterization. 88. p. 86-99. http://dx.doi.org/10.1016/j.matchar.2013.12.007

This was done for four samples, two reference samples and two weathered samples of both limestones at the end of the capillary uptake test. Because the bottom of the sample was placed 4-6 mm below the water level, no information was obtained for this zone. The moisture profiles for both the reference samples of Savonnières and Euville stones show a fluctuation of the maximal water content in the first $30 \mathrm{~mm}$ which is due to the heterogeneous character of both limestones. Because the initial water uptake was investigated, in most cases, the tests were stopped before the waterfront reached the surface of the sample. The focus of those test was to look how the weathering crust influences the initial water uptake (first minutes) inside the stones. Only in the case of the Euville reference sample that the waterfront reached the surface. In all other samples, the moisture content at higher positions gradually decreases because the waterfront did not reach the surface yet. It is found that the initial water uptake is faster for samples without weathering crust. This can be seen by the larger step sizes of the moisture content intervals. For both weathered stones, no significant maximal water content was obtained at a certain height, indicating that the weathering crust delays the uptake.

\subsubsection{Fluid Flow Modelling}

Flow paths were visualized with Avizo $^{\circledR}$ Fire in combination with XLAB HYDRO for the Euville stone before and after weathering (Fig. 13). This was done on the same HRXCT datasets that were used for the 3D analysis measurements by Morpho+. By visualizing those paths, it becomes visible that new paths are created by the dissolution and precipitation processes of the induced weathering (A inthe figure). Moreover, water migrates just below the newly formed gypsum layer, inducing new precipitation processes ( $B$ in the figure). This may explain, to some extent, why after 21 days of weathering the large interconnected pore network starts to fragmentise due to new crystallizations inside the pore structure.

\section{Discussion}

Weathering crusts of limestones have been studied extensively in many environments $[8,12,27,43,44]$. Sulphate formation occurs both on the stone surface as well as inside the pore structure of the stone. Many forms of gypsum crust are known and its formation highly depends on the environmental factors and on the internal properties of the stone. In this study, with the aid of HRXCT, weathering processes are quantified based on the transformations of the pore structure. In addition, water uptake experiments were performed on the unweathered and weathered materials in order to quantify the initial water uptake processes. The approach outlined here relies on a combination of HRXCT, 3D image analysis and the use of traditional microscopy techniques that can be employed on a variety of rocks and weathering processes. In this study, it is shown that the gypsum crust formation processes for the Euville and Savonnières limestones are completely different.

In the Savonnières limestone, the crystallization processes are concentrated in the partially dissolved ooid fragments and in the cortex and inside pre-existing microcracks. Only a thin external gypsum layer is present. This is also reflected in the stones used in monuments. The crystallization inside the stone resulted however in a decrease in porosity and a fragmentation of the open pore network. This complete conversion of the ooids was already observed in 2D [28,45]. In addition, also the oolitic limestones in Budapest (Hungary) were intensively investigated $[12,46]$. In these studies, a thick, framboidal black gypsum crust was observed around the ooid fragments and criss-cross inside microcracks of the ooids. The authors demonstrated the existence of idiomorphic 
Dewanckele, J., De Kock, T., Fronteau G., Derluyn, H., Vontobel, P., Dierick, M., Van Hoorebeke, L., Jacobs, P., Cnudde, V. 2014. Neutron radiography and $\mathrm{X}$-ray computed tomography for quantifying weathering and water uptake processes inside porous limestones used as building material. Materials Characterization. 88. p. 86-99. http://dx.doi.org/10.1016/j.matchar.2013.12.007

gypsum crystals on top of calcite cement and within the porous structure [46]. As Schiavon explained, the crystallization and conversion of ooid limestones depend on the microstructure of the stone, its texture and structure [45]. In the case of the Savonnières limestone, the cementation does not isolate the ooids from weathering fluids. The fluids can penetrate easily because of the residual intergranular, open porosity $[28,47]$. Because of the high microporosity and thus reactive surface of the ooid parts (who are partially dissolved), weathering acts first on those elements, and thus almost no conversion of the cement was found inside the Savonnières stone. The processes can somehow be compared with the crystallizations inside the highly-porous foraminifera of the Lede stone, acting as primary crystallization spots [19].

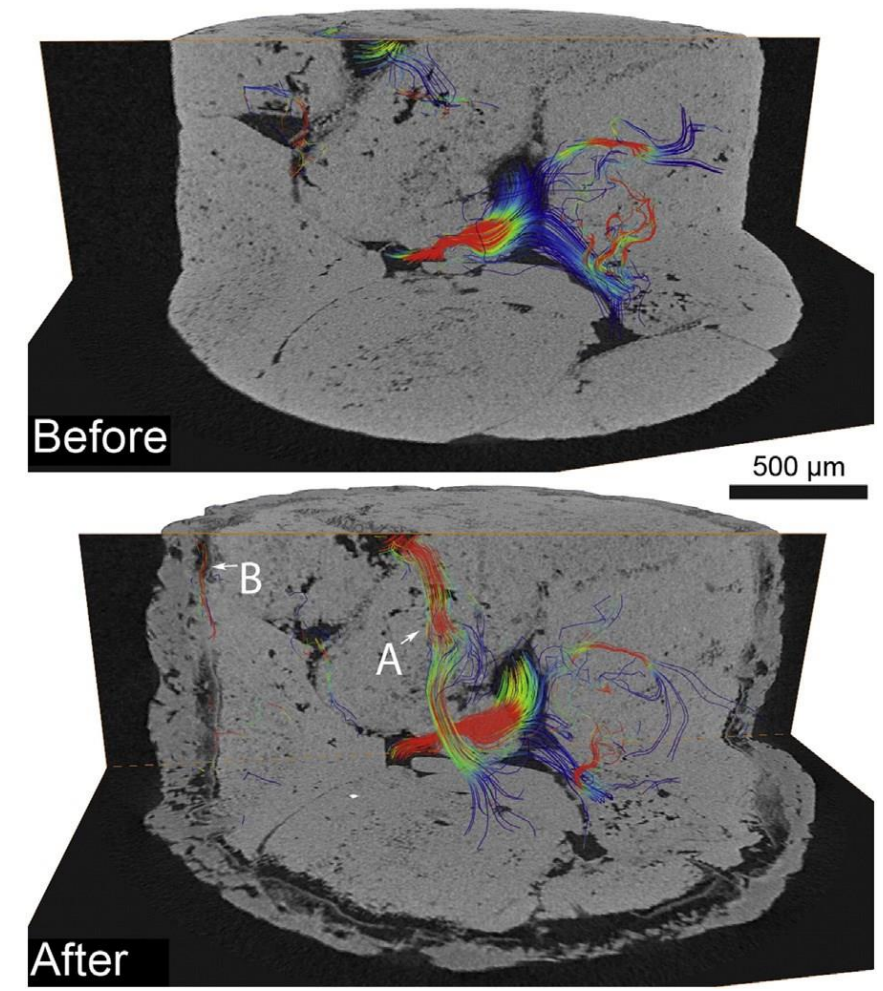

Fig. 13 - Fluid flow velocity paths in the Euville limestone before and after weathering. A and B: creation of new fluid paths.

In the case of the Euville stone, a thick external gypsum crust was identified with a porous dissolution zone underneath. The crinoid fragments were gradually attacked by the acid environment with a consequent conversion into gypsum as a result. Also, the syntaxial cement around the crinoid fragments was transformed into gypsum. The thick gypsum crust significantly prevented the stone from secondary weathering. For both the weathering of the syntaxial cement as well as for the crinoid fragments, the direction of the weathering follows the cleavage planes in the calcite monocrystals [28]. Quantification of the changes in radial intersections demonstrate that the external crust almost completely shields the surface, thus preventing gasses and water to interact with the stone. Due to the syntaxial overgrowth of the crinoid fragments, the observed weathering processes appeared to be similar to the processes described on the Carrara marble $[28,48]$.

The formation of gypsum crusts and accordingly, the change of the porous structure below will have its influence on the water uptake if the material becomes exposed to rain. Water absorption in porous limestones 
Dewanckele, J., De Kock, T., Fronteau G., Derluyn, H., Vontobel, P., Dierick, M., Van Hoorebeke, L., Jacobs, P., Cnudde, V. 2014. Neutron radiography and $X$-ray computed tomography for quantifying weathering and water uptake processes inside porous limestones used as building material. Materials Characterization. 88. p. 86-99. http://dx.doi.org/10.1016/j.matchar.2013.12.007

can cause severe problems, because the liquid can bring polluting particles, acids, dissolved salts, etc. in the interior of the stone. It was suggested that the formation of crust can prevent in some way the water uptake [49]. In this work, the water content was quantified using neutrons. The visualization of water with neutrons was already performed by various authors [50-55]. Some of them also used the QNI method for quantification of the moisture content $[56,57]$. By using neutrons as visualization and quantification methods, water content could be quantified in function of the height inside the sample and in function of time. As observed in Fig. 11, the calculated water content in the stones is lower than the gravimetrical measurements on the same sample after the neutron experiment. This can be due to a systematic under estimation of detector background in QNI or the fact that that there was a time difference of about 15 min between the acquisition of the last neutron image and the gravimetrical measurements, as it takes some time before the radiation level in the beamline has decreased enough to enter the bunker. In this way, the samples were left longer in contact with the water before gravimetrical measurements. A second contribution to the difference could be that the surface of the sample was 4-6 $\mathrm{mm}$ below the water surface. So, no quantification of the water content in this zone was obtained. However, the results with neutron radiography suggest that the water uptake in both weathered limestones is lower than the reference sample and the maximum water content was not reached inside the weathered stones during the duration of the test. This indicates that when a stone is weathered by the formation of a gypsum crust, it takes longer to fill the entire pore structure below the crust. In the case of the Euville stone, although the porosity increases after the weathering test, the gypsum crust and crystallization in the existing pore structure slow down the water uptake. The same process could be observed in the Savonnières stone. Although neutron radiography images are 2D and thus a sum of the water content along the thickness of the sample, it provides relevant information for water uptake processes in fresh and weathered building stones. On the otherhand,if onewants toseethe waterflow pathsin 3D,fluid flow simulations are mandatory. In this study simulations were only performed on the Euville stone because the percolating porosity inside the scanned Savonnières core was too low. The advantage of those simulations is that flow paths can be visualized and as can be seen in Fig. 13, fluids are able to migrate through the gypsum crust and occupy the porous spaces below.

Small samples sizes are crucial for very high resolution X-ray computed tomography. If for example crystallizations in the cortex or inside microcracks of the ooids want to be visualized and quantified in 3D, samples sizes decrease to several millimetre. However, working with small sample sizes raises the question of representative volume. The primary question, however, remains what characteristic or property does one want to see in 3D by means of X-ray? Is it to determine overall parameters like total porosity to be used as the overall porosity value for the stone in general? Or does one want to look in detail at a certain volume of interest in order to solve some remaining questions. Further research on this topic is mandatory to fill the gap between weathering on microscale and what happens with the whole stone structure when it is used in monuments.

\section{Conclusions}

Complete characterization on micron scale from crystallization processes to pore structure modification and fluid flow changes were conducted on two building materials, Euville and Savonnières limestones. By providing, in a non-destructive way, high resolution and high quality X-ray CT images before and after weathering, pore structure evolution could be revealed in three dimensions. 
Dewanckele, J., De Kock, T., Fronteau G., Derluyn, H., Vontobel, P., Dierick, M., Van Hoorebeke, L., Jacobs, P., Cnudde, V. 2014. Neutron radiography and $\mathrm{X}$-ray computed tomography for quantifying weathering and water uptake processes inside porous limestones used as building material. Materials Characterization. 88. p. 86-99. http://dx.doi.org/10.1016/j.matchar.2013.12.007

For the Euville limestone it can be noted that: (1) a thick $(200 \mu \mathrm{m})$ external gypsum layer is formed; (2) the porosity increases after 6 days of weathering and afterwards stagnated due to the protective character of the crust; and (3) the interconnectivity of the pore structure increases after 6 days of weathering and decreases again after 21 days. The latter phenomenon can be explained by a fragmentation of the porous layer below the crust due to internal crystallizations. In addition, after 21 days new pores were formed on top of the gypsum crust.

For the Savonnières limestone it can be concluded that: (1) porosity decreases after 6 and 21 days of gypsum crust formation; (2) crystallization is concentrated in the ooid fragments; (3) almost no external gypsum layer was visible; (4) interconnectivity of the pore network decreases and new pores are formed due to fragmentation; and (5) the open pore structure decreases.

For both limestones, the radial intersections of the open pore structure at the surface of the sample decreased. However, only for the Euville limestone almost all radial intersections were closed while for the Savonnières limestone only a slight decrease could be quantified.

In addition, it is shown that gypsum crusts on both limestones influence the initial water uptake. The experiment was done by using neutrons to quantify the water content in each time interval in function of the height inside the stone. For both the weathered stone samples, the initial uptake was slower and the maximum water content was not reached in the first stages of the uptake.

\section{Acknowledgements}

Part of this work is based on experiments at NEUTRA (http:// www.psi.ch/sinq/neutra), PSI, Villigen, Switzerland. The help of Delphine Vandevoorde, Marijn Boone, Matthieu Boone, Steven Peetermans, Jan Hovind and Tom Bultreys is greatly appreciated. The authors would also like to thank the Agency for Promotion and Innovation by Science and Technology in Flanders, Belgium (IWT) for the PhD grant of J. Dewanckele.

\section{REFERENCES}

[1] Camuffo D. Physical-weathering of stones. Sci Total Environ 1995;167:1-14.

[2] Dreesen R, Dusar M. Historical building stones in the province of Limburg (NE Belgium): role of petrography in provenance and durability assessment. Mater Charact 2004;53:273-87.

[3] Fronteau G, Moreau C, Thomachot-Schneider C, Barbin V. Variability of some Lutetian building stones from the Paris Basin, from characterisation to conservation. Eng Geol 2010;115:158-66.

[4] Smith BJ, Gomez-Heras M, McCabe S. Understanding the decay of stone-built cultural heritage. Prog Phys Geogr 2008;32:439-61.

[5] Dreesen R, Nielsen P, Lagrou D. Provenance, durability and damage analysis of natural building stones by means of petrographical techniques. Fracture and failure of natural building stones; 2006 471-85.

[6] Török Á, Licha T, Simon K, Siegesmund S. Urban and rural limestone weathering; the contribution of dust to black crust formation. Environ Earth Sci 2011;63:675-93.

[7] Ortiz P, Vazquez MA, Ortiz R, Martin JM, Ctvrtnickova T, Mateo MP, et al. Investigation of environmental pollution effects on stone monuments in the case of Santa Maria La Blanca, Seville (Spain). Appl Phys A: Mater Sci Process 2010;100:965-73. 
Dewanckele, J., De Kock, T., Fronteau G., Derluyn, H., Vontobel, P., Dierick, M., Van Hoorebeke, L., Jacobs, P., Cnudde, V. 2014. Neutron radiography and $\mathrm{X}$-ray computed tomography for quantifying weathering and water uptake processes inside porous limestones used as building material. Materials Characterization. 88. p. 86-99. http://dx.doi.org/10.1016/j.matchar.2013.12.007

[8] Maravelaki-Kalaitzaki P, Biscontin G. Origin, characteristics and morphology of weathering crusts on Istria stone in Venice. Atmos Environ 1999;33:1699-709.

[9] Montana G, Randazzo L, Oddo IA, Valenza M. The growth of "black crusts" on calcareous building stones in Palermo (Sicily): a first appraisal of anthropogenic and natural sulphur sources. Environ Geol 2008;56:367-80.

[10] Dolske DA. Deposition of atmospheric pollutants to monuments, statues, and buildings. Sci Total Environ 1995;167:15-31.

[11] Matovic V, Eric S, Kremenovic A, Colomban P, Sreckovic-Batocanin D, Matovic N. The origin of syngenite in black crusts on the limestone monument King's Gate (Belgrade Fortress, Serbia) - the role of agriculture fertiliser. J Cult Herit 2012;13:175-86.

[12] Török Á, Rozgonyi N. Morphology and mineralogy of weathering crusts on highly porous oolitic limestones, a case study from Budapest. Environ Geol 2004;46:333-49.

[13] Sanchez JS, Alves CAS, Romani JRV, Mosquera DF. Origin of gypsum-rich coatings on historic buildings. Water Air Soil Pollut 2009;204:53-68.

[14] Montana G, Randazzo L, Mazzoleni P. Natural and anthropogenic sources of total suspended particulate and their contribution to the formation of black crusts on building stone materials of Catania (Sicily). Environ Earth Sci 2012;67:1097-110.

[15] McAlister JJ, Smith BJ, Török Á. Element partitioning and potential mobility within surface dusts on buildings in a polluted urban environment, Budapest. Atmos Environ 2006;40:6780-90.

[16] Cardell-Fernandez C, Vleugels G, Torfs K, Van Grieken R. The processes dominating Ca dissolution of limestone when exposed to ambient atmospheric conditions as determined by comparing dissolution models. Environ Geol 2002;43:160-71.

[17] Charola AE, Puhringer J, Steiger M. Gypsum: a review of its role in the deterioration of building materials. Environ Geol 2007;52:207-20.

[18] Fronteau G, Barbin V, Pascal A. Impact of sedimentary-diagenetic facies on weathering of carbonate building stone. C R Acad Sci IIA Earth Planet Sci 1999;328:671-7.

[19] Dewanckele J, Boone MA, De Kock T, De Boever W, Brabant L, Boone MN, et al. Holistic approach of preexisting flaws on the decay of two limestones. Sci Total Environ 2013;447:403-14.

[20] Dewanckele J, De Kock T, Boone MA, Cnudde V, Brabant L, Boone MN, et al. 4D imaging and quantification of pore structure modifications inside natural building stones by means of high resolution X-ray CT. Sci Total Environ 2012;416:436-48.

[21] NBN EN 13919. Natural stone test methods-determination of resistance to ageing by SO2 action in the presence of humidity; 2003.

[22] Lanzon M, Cnudde V, de Kock T, Dewanckele J. X-ray microtomography (mu-CT) to evaluate microstructure of mortars containing low density additions. Cement Concr Compos 2012;34:993-1000.

[23] Cnudde V, Dewanckele J, Boone M, de Kock T, Boone M, Brabant L, et al. High-resolution X-Ray CT for 3D petrography of ferruginous sandstone for an investigation of building stone decay. Microsc Res Tech 2011;74:1006-17.

[24] Camuffo D, Delmonte M, Sabbioni C. Origin and growth mechanisms of the sulfated crusts on urban limestone. Water Air Soil Pollut 1983;19:351-9. 
Dewanckele, J., De Kock, T., Fronteau G., Derluyn, H., Vontobel, P., Dierick, M., Van Hoorebeke, L., Jacobs, P., Cnudde, V. 2014. Neutron radiography and $X$-ray computed tomography for quantifying weathering and water uptake processes inside porous limestones used as building material. Materials Characterization. 88. p. 86-99. http://dx.doi.org/10.1016/j.matchar.2013.12.007

[25] Ausset P, Crovisier JL, DelMonte M, Furlan V, Girardet F, Hammecker C, et al. Experimental study of limestone and sandstone sulphation in polluted realistic conditions: the

Lausanne Atmospheric Simulation Chamber (LASC) (vol 30, pg 3197, 1996). Atmos Environ 1996;30:3197-207.

[26] Boke H, Gokturk EH, Caner-Saltik EN, Demirci S. Effect of airborne particle on SO2-calcite reaction. Appl Surf Sci 1999;140:70-82.

[27] Siegesmund S, Török Á, Hupers A, Muller C, Klemm W. Mineralogical, geochemical and microfabric evidences of gypsum crusts: a case study from Budapest. Environ Geol 2007;52:369-81.

[28] Fronteau G, Schneider-Thomachot C, Chopin E, Barbin V, Mouze D, Pascal A. Black-crust growth and interaction with underlying limestone microfacies. Geochem Soc Spec Publ 2010:25-34.

[29] Sanchez JS, Romani JRV, Alves C. Deposition of particles on gypsum-rich coatings of historic buildings in urban and rural environments. Constr Build Mater 2011;25:813-22.

[30] Mcgee ES, Mossotti VG. Gypsum accumulation on carbonate stone. Atmos Environ B-Urb 1992;26:24953.

[31] Yerrapragada SS, Chirra SR, Jaynes JH, Li S, Bandyopadhyay JK, Gauri KL. Weathering rates of marble in laboratory and outdoor conditions. J Environ Eng ASCE 1996;122:856-63.

[32] Masschaele BC, Cnudde V, Dierick M, Jacobs P, Van Hoorebeke L, Vlassenbroeck J. UGCT: new X-ray radiography and tomography facility. Nucl Inst Methods Phys Res A 2007;580:266-9.

[33] Vlassenbroeck J, Masschaele BC, Dierick M, Cnudde V, De Witte Y, Pieters K, et al. Recent developments in the field of X-ray nano- and micro-CT at the Centre for X-ray Tomography of the Ghent University. Microsc Microanal 2007;13:184-5.

[34] Dierick M, Masschaele B, Van Hoorebeke L. Octopus, a fast and user-friendly tomographic reconstruction package developed in LabView (R). Meas Sci Technol 2004;15:1366-70.

[35] Brabant L, Vlassenbroeck J, De Witte Y, Cnudde V, Boone MN, Dewanckele J, et al. Three-dimensional analysis of high-resolution X-ray computed tomography data with Morpho+. Microsc Microanal 2011;17:252-63.

[36] Lehmann E, Vontobel P, Wiezel L. Properties of the radiography facility NEUTRA at SINQ and its potential for use as European reference facility. Nondestruct Test Eval 2001;16:191-202.

[37] Hassanein R, Meyer HO, Carminati A, Estermann M, Lehmann E, Vontobel P. Investigation of water imbibition in porous stone by thermal neutron radiography. J Phys D Appl Phys 2006;39:4284-91.

[38] Hassanein R, Lehmann E, Vontobel P. Methods of scattering corrections for quantitative neutron radiography. Nucl Inst Methods Phys Res A 2005;542:353-60.

[39] David J, Roux M. Modèle actuel de production bioclastique par les crinoïds pédonculés. Earth Planet Sci 2000;330:111-6.

[40] Dusar M, Dreesen R, De Naeyer A. Natuursteen in Vlaanderen, versteend verleden. Mechelen: Wolters Kluwer België NV; 2009.

[41] De Kock T. De ledesteen en zijn hedendaagse vervangstenen: een vergelijkende studie. Geology and soil science, Ghent University, Ghent, Belgium; 2009205.

[42] Cnudde V, Dewanckele J, De Ceukelaire M, Everaert G, Jacobs. P, Laleman MC. Gent...Steengoed! Gent, Belgium: Academia Press; 2009. 
Dewanckele, J., De Kock, T., Fronteau G., Derluyn, H., Vontobel, P., Dierick, M., Van Hoorebeke, L., Jacobs, P., Cnudde, V. 2014. Neutron radiography and $X$-ray computed tomography for quantifying weathering and water uptake processes inside porous limestones used as building material. Materials Characterization. 88. p. 86-99. http://dx.doi.org/10.1016/j.matchar.2013.12.007

[43] Török Á. Surface strength and mineralogy of weathering crusts on limestone buildings in Budapest. Build Environ 2003;38:1185-92.

[44] Smith BJ, Török Á, McAlister JJ, Megarry Y. Observations on the factors influencing stability of building stones following contour scaling: a case study of oolitic limestones from Budapest, Hungary. Build Environ 2003;38:1173-83.

[45] Schiavon N. BSEM study of decay mechanisms in urban oolitic limestones. Eur Cult Herit 1992;6:35-46.

[46] Török Á. Oolitic limestone in a polluted atmospheric environment in Budapest: weathering phenomena and alterations in physical properties. Natural stone, weathering phenomena, conservation strategies and case studies; 2002 363-79.

[47] Roels S, Carmeliet J, Hens H. Modelling unsaturated moisture transport in heterogeneous limestone(part 1. A mesoscopic approach). Transport Porous Med 2003;52:333-50.

[48] Vergesbelmin V. Pseudomorphism of gypsum after calcite, a new textural feature accounting for the marble sulfation mechanism. Atmos Environ 1994;28:295-304.

[49] Thomachot-Schneider C, Gommeaux M, Fronteau G. Modifications of the porous network of sandstone accompanying the formation of black varnish. Environ Geol 2008;56:571-82.

[50] Cnudde V, Dierick M, Vlassenbroeck J, Masschaele B, Lehmann E, Jacobs P, et al. High-speed neutron radiography for monitoring the water absorption by capillarity in porous materials. Nucl Instrum Meth Phys Res B 2008;266:155-63.

[51] Masschaele B, Dierick M, Van Hoorebeke L, Cnudde V, Jacobs P. The use of neutrons and monochromatic X-rays for non-destructive testing in geological materials. Environ Geol 2004;46:486-92.

[52] Shokri N, Lehmann P, Vontobel P, Or D. Drying front and water content dynamics during evaporation from sand delineated by neutron radiography. Water Resour Res 2008;44.

[53] Pel L, Ketelaars AAJ, Adan OCG, Vanwell AA. Determination of moisture diffusivity in porous-media using scanning neutron radiography. Int J Heat Mass Transfer 1993;36:1261-7.

[54] Zhang P, Wittmann FH, Zhao T, Lehmann EH. Neutron imaging of water penetration into cracked steel reinforced concrete. Phys B Condens Matter 2010;405:1866-71.

[55] Masschaele B, Dierick M, Cnudde V, Van Hoorebeke L, Delputte S, Gildemeister A, et al. High-speed thermal neutron tomography for the visualization of water repellents, consolidants and water uptake in sand and lime stones. Radiat Phys Chem 2004;71:807-8.

[56] Derluyn H, Griffa M, Mannes D, Jerjen I, Dewanckele J, Vontobel P, et al. Characterizing saline uptake and salt distributions in porous limestone with neutron radiography and X-ray micro-tomography. J Build Phys 2013;36:353-74.

[57] Van Tittelboom K, Snoeck D, Vontobel P, Wittmann FH, De Belie N. Use of neutron radiography and tomography to visualize the autonomous crack sealing efficiency in cementitious materials. Mater Struct 2013;46:105-21. 